\title{
Implementasi Sistem Komunikasi FM Pada Prototype Pendeteksi Dini Gempa
}

\author{
Atik Charisma \\ Jurusan Teknik Elektro, \\ Fakultas Teknik \\ Universitas Jenderal Achmad Yani \\ J1. Terusan Jenderal Sudirman PO \\ BOX 148,Cimahi, Jawa Barat, \\ Indonesia \\ atikcharisma@gmail.com \\ Muhammad Burhannudin \\ Misuari \\ Jurusan Teknik Elektro, \\ Fakultas Teknik \\ Universitas Jenderal Achmad Yani \\ Jl. Terusan Jenderal Sudirman PO \\ BOX 148,Cimahi, Jawa Barat, \\ Indonesia
}

\author{
Een Taryana \\ Jurusan Teknik Elektro, \\ Fakultas Teknik \\ Universitas Jenderal Achmad Yani \\ Jl. Terusan Jenderal Sudirman PO \\ BOX 148,Cimahi, Jawa Barat, \\ Indonesia
}

\author{
Aldi Setiawan \\ Jurusan Teknik Elektro, \\ Fakultas Teknik \\ Universitas Jenderal Achmad Yani \\ Jl. Terusan Jenderal Sudirman PO \\ BOX 148,Cimahi, Jawa Barat, \\ Indonesia
}

\author{
Dede Irawan Saputra \\ Jurusan Teknik Elektro, \\ Fakultas Teknik \\ Universitas Jenderal Achmad Yani \\ Jl. Terusan Jenderal Sudirman PO \\ BOX 148,Cimahi, Jawa Barat, \\ Indonesia
}

\author{
Faisal Dharmawan \\ Jurusan Teknik Elektro, \\ Fakultas Teknik \\ Universitas Jenderal Achmad Yani \\ J1. Terusan Jenderal Sudirman PO \\ BOX 148,Cimahi, Jawa Barat, \\ Indonesia
}

\begin{abstract}
An earthquake is a vibration that occurs due to plates at the base of the earth rubbing against each other. An earthquake can have several impacts, namely material loss and loss of life and trauma for some people who feel it. This happens because people are not fast enough in getting information. Therefore we need an earthquake detection device that is relatively inexpensive. In this study designed a prototype for earthquake early detection using Frequency Modulation (FM) communication. The components of this system are Arduino Uno which functions as a microcontroller, SW-420 vibration sensor to detect vibrations, buzzer as the output of the $\mathrm{SW}-420$ sensor in the form of sound and FM transmitter V2.0 which functions as a medium for transmitting radio frequency signals and sending sound from the buzzer. The level of vibration that indicates that an earthquake occurred namely 3-5 with a conversion of 5-10 SR. The system would have the ability to provide information in the form of sound received by a radio or $F M$ receiver. The distance that can be emitted by the FM transmitter module V2.0 is 17.87 meter
\end{abstract}

Keyword - earthquake; arduino; FM transmitter V2.0; SW-420 sensor

\section{PENDAHULUAN}

Indonesia merupakan salah satu negara yang berada di jalur gempa teraktif di dunia atau dikenal dengan istilah cincin api. Hal ini karena Indonesia dikelilingi oleh cincin api pasifik dan di atas tiga tumpukan lempeng yaitu Indo-Asutralia, Eurasia dan Pasifik. Indonesia juga memiliki gunung-gunung yang masih aktif seperti gunung anak Krakatau dan gunung Merapi. Maka dari itu, Indonesia sangat rentan terjadinya gempa tektonik maupun vulkanik. Bahkan gempa yang terjadi di Indonesia dapat menimbulkan tsunami.
Litosfer adalah lapisan bumi terluar yang erat kaitannya dengan proses gempa[1]. Gempa bumi merupakan sebuah guncangan hebat yang menjalar ke permukaan bumi di dalam litosfer[2]. Lapisan kulit bumi mempunyai temperatur relative jauh lebih rendah dibandingkan lapisan dibawahnya sehingga terjadi aliran konvektif yaitu massa dengan suhu tinggi mengalir ke daerah bersuhu lebih rendah. Akibat gerakan ini maka kulit bumi terpecah-pecah menjadi bagian-bagian berupa lempengan yang saling bergerak satu sama lain. Semakin lama gerakan tersebut sehingga menimbulkan tekanan yang semakin membesar dan akhirnya mencapai suatu keadaan tekanan tersebut tidak dapat ditahan lagi oleh pinggiran lempengan. Pada saat itulah gempa bumi terjadi yang energinya menjalar ke berbagai arah[3].

Berawal dari gempa Aceh tanggal 26 Desember 2004 dan Sumatera Barat 30 September 2008 yang menimbulkan banyak korban jiwa. Seiring dengan berjalannya waktu gempa bumi pun sering terjadi seperti pada tanggal 28 September 2018 di Palu dan Donggala serta di Banten tanggal 2 Agustus 2019. Kejadian tersebut menimbulkan beberapa dampak baik kerugian material maupun korban jiwa serta trauma bagi sebagian orang yang mengalaminya. Hal ini terjadi kerena kurangnya informasi yang diperoleh masyarakat ketika gempa terjadi.

Penelitian tentang pendeteksian dini gempa memang sedang giat dilakukan. Terdapat beberapa penelitian terkait pendeteksian gempa yakni [3]melakukan simulasi penerimaan dengan memancarkan gelombang daya kecil untuk mendeteksi gempa. Gelombang tersebut diterima oleh penerima FM dan komputer. Daya pancar gelombang kemudian dinaikkan untuk mensimulasikan peningkatan daya pancar akibat perubahan lapisan 
ionosfir yang mana ini pertanda bahwasannya terjadi sebuah gempa.

Penelitian lain [4]merancang sebuah prototype pendeteksi dini gempa berdasarkan fluktuasi medan magnet. Prototype ini merupakan alat yang dapat mendeteksi adanya getaran dan dengan dua output LED serta buzzer. Tidak hanya itu [5] membangun prototype sistem monitoring getaran gempa dengan menggunakan sensor module SW-420. Sensor ini berfungsi untuk mendeteksi getaran sebagai indikasi bahwa itu adalah gempa dengan mengintegrasikan Raspberry Pi sebagai mikrokontroler dan modul LoRa yang berbasis teknologi Low Power Wide Area Network ( $L P-W A N)$. Sistem ini mampu menunjukkan titik koordinat lokasi secara real time.

Prototype pendeteksi getaran gempa dengan sensor getaran menggunakan android berbasis mikrokontroler diteliti oleh[6]. Alat ini menggunakan module wifi esp 8266 sebagai transmitter dan receiver yang nantinya akan mengirimkan informasi berupa gelombang getaran ke layar android. Selain itu [7] merancang sistem alarm gempa bumi menggunakan prinsip gaya pegas dan penginderaan medan magnetik. Sistem ini memanfaatkan prinsip gaya pegas dan penginderaan medan magnet menggunakan sensor Efek Hall.

Pemerintah memang sudah memiliki alat pendeteksi dini gempa namun harga alat tersebut relatif mahal. Alat ini hanya dipasang pada daerah tertentu yang rawan akan bencana gempa. Namun tidak semua kalangan masyarakat memperoleh informasi ketika gempa terjadi karena jangkauan alat yang dipasang oleh pemerintah tidak terlalu jauh. Salah satu alat komunikasi yang umumnya sudah dimiliki oleh masyarakat adalah radio. Radio menggunakan teknik modulasi frekuensi (Frequency Modulation FM) yang mana harga alat teknologi ini jauh lebih murah dan bisa menjangkau daerah yang lebih luas. Oleh karena itu penelitian ini merancang prototype alat pendeteksi dini gempa dengan memanfaatkan sinyal FM. Penelitian ini diharapkan dapat memberikan informasi ke masyarakat ketika terjadi gempa serta dengan harga yang relatif lebih murah.

Frequency Modulation atau yang dikenal dengan istilah modulasi frekuensi (FM) didefinisikan sebagai debiasi frekuensi sesaat sinyal pembawa sesuai dengan amplitudo sesaat sinyal pemodulasi. Pada modulasi frekuensi yang mana frekuensi sinyal pembawa diubah-ubah sehingga besarnya sebanding dengan besarnya amplitude sinyal pemodulasi. Semakin besar amplitude sinyal pemodulasi maka semakin besar pula frekuensi sinyal termodulasi FM.

Pada awalnya sinyal FM digunakan oleh penelitipeneliti sebelumnya untuk mengamati komet. Pada Agustus 1993, Y Kushida seorang ahli astronom dari Jepang mengamati bahwasannya terdapat karakter yang berbeda dengan gelombang hasil pantulan komet dengan menggunakan metode FM. Hal ini terjadi karena adanya kelainan gelombang pada stasiun penerima FM yang ada hubungannya dengan aktivitas lapisan bumi. Hipotesis ini menjadi awal mulanya metode FM untuk mendeteksi dini gempa. S.
Fukushima terinspirasi dari Y Kushida, ia berhasil mendeteksi fenomena elektromagnetik berupa peningkatan level noise elektromagnetik sebelum terjadi gempa.

Pemantulan gelombang ionosfir terjadi bila adanya :

1. Pesawat terbang

2. Aktivitas matahari

3. Aktivitas meteor

4. Gejala sebelum terjadinya gempa.

Pemantulan gelombang pada ionosfir tersebut akan meningkatkan jangkauan pemancar FM (meningkatkan daya penerimaan). Memprediksi gempa dengan metode FM sangatlah mungkin untuk diterapkan karena teknologinya murah dan umumnya semua kalangan masyarakat sudah menggunakan teknologi ini.

\section{METODE}

Metode penelitian merupakan salah satu bagian penting dari tahapan penelitian. Metode penelitian ditetapkan terlebih dahulu sebelum memecahkan masalah yang akan dibahas agar penelitian menjadi terarah, sistematis serta memudahkan dalam menganalisis permasalahan[8].

\section{A. Blok Diagram Sistem}

Perancangan melalui simulasi menjadi langkah awal dalam penelitian ini. Sistem ini terdapat beberapa bagian seperti pada Gambar 1 bagian pertama merpakan sebuah input menggunakan sensor getar kemudian mikrokontroler serta bagian terakhir adalah output berupa alarm yang bunyinya akan dipancarkan melalui FM transmitter.

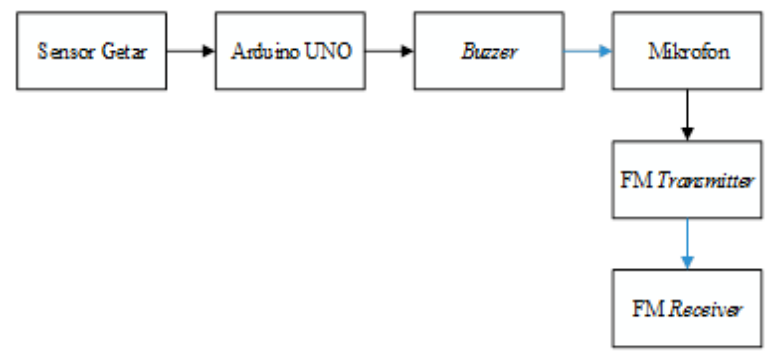

Gambar 1. Blok Diagram Sistem

Keterangan :

Hubungan dengan kabel :

Hubungan tanpa kabel

\section{B. Diagram Alir Penelitian}

Inisialisasi getaran merupakan langkah pertama dari sistem ini seperti pada Gambar 2 yang mana akan memberikan data pada sensor getar. Sensor getar akan mendeteksi adanya sebuah getaran. Sensor akan aktif jika terjadi sebuah getaran jika tidak ada getaran maka sensor akan kembali ke proses inisialisasi sensor. Getaran yang diterima oleh sensor getar melalui proses di mikrokontroller maka akan diteruskan ke buzzer sebagai alarm bahwasannya sensor menangkap sebuah getaran yang berpotensi sebagai gempa. Jika getaran terdeteksi sebagai gempa maka buzzer aktif dan akan menimbulkan suara sebagai alarm dan jika 
tidak akan kembali ke proses inisialisasi. Suara yang dikeluarkan oleh buzzer akan diteruskan ke FM transmitter untuk melakukan proses pengiriman informasi. Pengiriman informasi dipancarkan oleh sinyal FM di frekuensi 94,2 $\mathrm{MHz}$ yang bisa didengar oleh masyarakat melalui radio sebagai FM receiver.

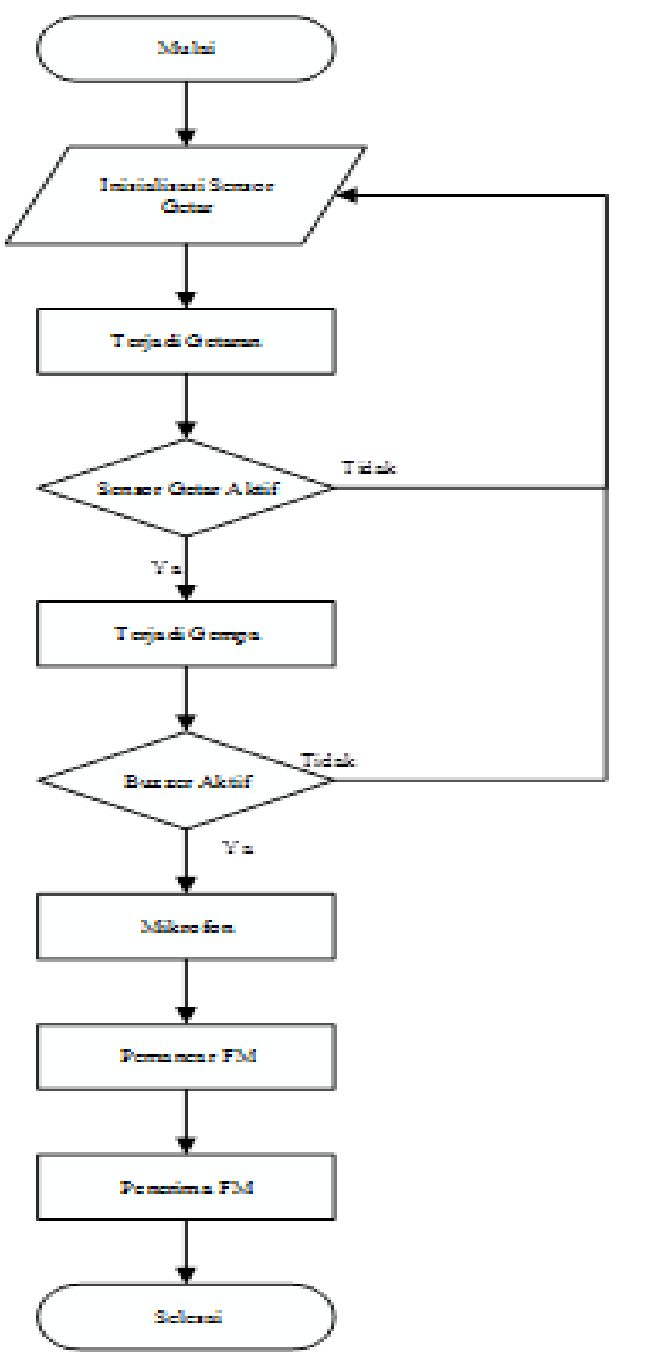

Gambar 2. Diagram Alir Penelitian

C. Perancangan Rangkaian Keseluruhan

Pada Gambar 3, instalasi rangkaian transmitter prototype alat pendeteksi dini gempa dengan menggunakan sinyal FM. Pada rangkaian tersebut sensor yang digunakan berupa sensor getar tipe SW-420 dan alat pendukung seperti buzzer untuk mengeluarkan suara sebagai pertanda bahwa ada getaran yang mengindikasi terjadinya gempa. FM transmitter V2.0 yang berfungsi sebagai pemancar FM agar suara yang dikeluarkan oleh buzzer dapat didengar oleh masyarakat melalui FM receiver berupa radio atau radio di handphone bahwa telah terjadi getaran yang berpotensi sebagai gempa.

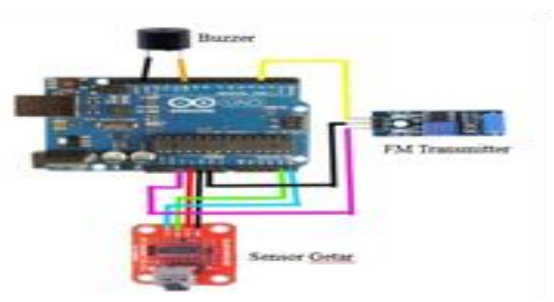

Gambar 3. Rangkaian Transmitter
Tabel 1. Konfigurasi Sensor SW-420

\begin{tabular}{|l|l|}
\hline Kaki Sensor & \multicolumn{1}{|c|}{ Hubungan Kabel } \\
\hline VCC & 3,3 Volt board Arduino Uno \\
\hline GND & Ground board Arduino Uno \\
\hline DO & Digital Pin 3 board Arduino Uno \\
\hline
\end{tabular}

Pada tabel 1 konfigurasi sensor SW-420 yang memiliki 3 kaki yaitu VCC, ground dan digital output. Setiap kakinya disambungkan dengan Arduino Uno agar diperoleh sebuah nilai referensi[9]. Kaki VCC dihubungkan dengan pin 3,3 Volt board Arduino Uno, kaki ground dengan ground board Arduino Uno dan digital output ke pin digital no 3 pada board Arduino Uno.

Tabel 2. konfigurasi fm transmitter V2.0

\begin{tabular}{|l|l|}
\hline Kaki Modul & \multicolumn{1}{|c|}{ Hubungan Kabel } \\
\hline VCC & 5 Volt board Arduino Uno \\
\hline GND & Ground board Arduino Uno \\
\hline SDA & Analog Pin A4 board Arduino Uno \\
\hline SCL & Analog Pin A5 board Arduino Uno \\
\hline
\end{tabular}


Pada tabel 2 konfigurasi FM transmitter V2.0 memiliki 4 kaki yaitu VCC, ground, SDA dan SCL. Setiap kaki terhubung dengan pin Arduino Uno. Kaki VCC terhubung dengan pin 5 Volt board Arduino Uno, kaki ground terhubung dengan ground board Arduino Uno, kaki SDA terhubung dengan pin analog A4 board Arduino Uno dan kaki SCL terhubung dengan pin analog A5 board Arduino Uno.

Tabel 3. Konfigurasi Buzzer

\begin{tabular}{|l|l|}
\hline Kaki Buzzer & Hubungan ke board Arduino Uno \\
\hline Kaki + & Digital Pin 10 board Arduino Uno \\
\hline Kaki - & Ground board Arduino Uno \\
\hline
\end{tabular}

Tabel 3 konfigurasi buzzer ini memiliki 2 kaki yaitu kaki (+) dan kaki (-). Setiap kaki terhubung dengan pin board Arduino Uno. Kaki (+) terhubung dengan pin digital output 10 board Arduino Uno dan kaki (-) terhubung dengan ground board Arduino Uno.

\section{HASIL DAN PEMBAHASAN}

Pada bagian ini akan menjelaskan tentang pengujian dan analisis sistem. Pengujian pada alat prototype pendeteksi gempa menggunakan transmisi sinyal radio FM berbasis Arduino Uno. Pengujian dan analisis ini bertujuan untuk mengetahui sistem dapat bekerja sesuai dengan fungsinya. Analisis akan dilakukan terhadap hasil yang ditunjukkan selama pengujian.

\section{A. Tegangan Input dan Output SW-420}

Pengujian ini bertujuan untuk mengetahui tegangan keluaran yang diperoleh sensor SW-420 sesuai dengan tegangan yang diterima. Getaran akan menghasilkan sebuah tegangan keluaran yang akan dihitung sehingga dapat dibandingkan dengan tegangan masukan. Gambar 4. akan menunjukan pengujian tegangan input sensor getaran ini.

Pada tabel 4. merupakan hasil pengukuran tegangan input dari sensor SW-420 dengan menggunakan multimeter digital. Hasil dari pengukuran tegangan input sensor ini tidak berbeda jauh dengan masukannya dari Arduino Uno.

Tabel 4. Hasil Pengujian Tegangan Input Sensor Getar SW-420

\begin{tabular}{|l|l|}
\hline Tegangan Input & Hasil Pengukuran \\
\hline 3,3 VDC & 3,287 VDC \\
\hline
\end{tabular}

Pada tabel 5 merupakan hasil dari pengukuran tegangan keluaran sensor SW-420, pada tegangan keluaran sensor SW420 saat tidak bergetar memiliki nilai sebesar 0,107 dan 0,106 VDC dan pada saat bergetar memiliki nilai sebesar 2,911, 2,963 dan 2,786 VDC. Sumber getaran untuk prototype ini menggunakan sebuah alat pijit yang dapat menimbulkan getaran dengan level 1-5. Pada level 1-2 sensor getar tidak aktif sedangkan ketika dimulai pada level 3, sensor baru aktif (bergetar)

Tabel 5. Hasil Pengujian Tegangan Output Sensor Getar SW-420

\begin{tabular}{|l|c|l|l|}
\hline \multirow{2}{*}{ Pengujian } & \multirow{2}{*}{$\begin{array}{c}\text { Tegangan } \\
\text { Masukan (VDC) }\end{array}$} & \multicolumn{2}{|c|}{ Keluaran } \\
\cline { 3 - 4 } & & & $\begin{array}{c}\text { Tegangan } \\
\text { (VDC) }\end{array}$ \\
\hline \multirow{2}{*}{1} & \multirow{2}{*}{3,3} & 0 (tidak bergetar) & 0,107 \\
\cline { 3 - 4 } & & 1 (bergetar) & 2,911 \\
\hline \multirow{2}{*}{3} & \multirow{2}{*}{3,3} & 0 (tidak bergetar) & 0,106 \\
\cline { 3 - 4 } & & 1 (bergetar) & 2,963 \\
\cline { 3 - 4 } & \multirow{2}{*}{3,3} & 0 (tidak bergetar) & 0,106 \\
\cline { 3 - 4 } & & 1 (bergetar) & 2,786 \\
\hline
\end{tabular}

\section{B. Pengujian Pulsa Output Sensor Getar SW-420}

Pengujian ini bertujuan untuk mengetahui sensor getar berfungsi dengan baik, seperti menangkap adanya getaran yang terjadi. Getaran tersebut akan disampaikan kepada buzzer untuk menjadi bunyi sebagai tanda bahwa terjadi sebuah getaran.

Pengujian sensor getar tidak hanya menjadi pertanda bahwa terjadi gempa atau tidak. Pada penelitian ini mencoba untuk mengkonversikan kekuatan getaran yang dihasilkan oleh sensor ke dalam kekuatan gempa dalam bentuk Skala Ricther (SR). Pengujian dilakukan 10 kali dengan 5 level getaran yang berbeda. Tabel 6 merupakan hasil getaran yang diterima oleh sensor dengan level yang berbeda, setiap pulsa dengan level tertentu menggunakan perbandingan 1:6000 untuk dikonversikan ke dalam Skala Richter (SR). Pada level 1-2 pulsa yang dihasilkan sangat kecil, jadi diisyaratkan bahwa kekuatan gempa di bawah 5 SR. Penelitian ini hanya membahas kekuatan gempa di atas 5 SR karena dengan kekuatan gempa sebesar itu yang dapat menimbulkan korban jiwa dan berpotensi tsunami.

Pada level 3 mendapatkan rata - rata nilai 16.322,6 dari 10x percobaan diatas. Percobaan ke-4 mendekati nilai rata rata dengan nilai 16.318 dan percobaan ke-3 jauh dari rata rata dengan nilai 11.045. Maka dari itu diperlukan 10x percobaan untuk mengetahui nilai yang efektif untuk mengurangi kesalahan. Pada level 3 ini disetarakan dengan kekuatan 5-6 skala richter.

Pada level 4 mendapatkan rata - rata nilai 22.889,9 dari 10x percobaan diatas. Percobaan ke-10 mendekati nilai rata rata dengan nilai 21.948 dan percobaan ke-1 jauh dari rata rata dengan nilai 30.632. Maka dari itu diperlukan 10x percobaan 4 untuk mengetahui nilai yang efektif untuk mengurangi kesalahan. Pada level 4 ini disetarakan dengan kekuatan $7-8$ skala richter.

Pada level 5 mendapatkan rata - rata nilai 38.602,4 dari 10x percobaan diatas. Percobaan ke-6 mendekati nilai rata rata dengan nilai 30.514 dan percobaan ke-1 jauh dari rata rata dengan nilai 44.252. Maka dari itu diperlukan 10x percobaan untuk mengetahui nilai yang efektif untuk mengurangi kesalahan. Pada level 5 ini disetarakan dengan kekuatan 9-10 skala richter.

Tabel 6. Hasil Pengujian Sensor Getar SW-420

\begin{tabular}{|c|c|c|c|}
\hline \multicolumn{2}{|c|}{ Percobaan 1} & \multicolumn{2}{|c|}{ Percobaan 2} \\
\hline $\begin{array}{c}\text { Level } \\
\text { Percobaan }\end{array}$ & $\begin{array}{c}\text { Keluaran Sensor } \\
\text { (Pulsa) }\end{array}$ & $\begin{array}{c}\text { Level } \\
\text { Percobaan }\end{array}$ & $\begin{array}{c}\text { Keluaran Sensor } \\
\text { (Pulsa) }\end{array}$ \\
\hline Level 3 & 19743 & Level 3 & 19921 \\
\hline Level 4 & 30632 & Level 4 & 21208 \\
\hline Level 5 & 44252 & Level 5 & 34261 \\
\hline \multicolumn{2}{|c|}{ Percobaan 3} & \multicolumn{2}{|c|}{ Percobaan 4} \\
\hline $\begin{array}{c}\text { Level } \\
\text { Percobaan }\end{array}$ & $\begin{array}{c}\text { Keluaran Sensor } \\
\text { (Pulsa) }\end{array}$ & $\begin{array}{c}\text { Level } \\
\text { Percobaan }\end{array}$ & $\begin{array}{c}\text { Keluaran Sensor } \\
\text { (Pulsa) }\end{array}$ \\
\hline Level 3 & 11045 & Level 3 & 16318 \\
\hline Level 4 & 21313 & Level 4 & 25323 \\
\hline Level 5 & 34265 & Level 5 & 40293 \\
\hline \multicolumn{2}{|c|}{ Percobaan 5} & \multicolumn{2}{|c|}{ Percobaan 6} \\
\hline $\begin{array}{c}\text { Level } \\
\text { Percobaan }\end{array}$ & $\begin{array}{c}\text { Keluaran Sensor } \\
\text { (Pulsa) }\end{array}$ & $\begin{array}{c}\text { Level } \\
\text { Percobaan }\end{array}$ & $\begin{array}{c}\text { Keluaran Sensor } \\
\text { (Pulsa) }\end{array}$ \\
\hline Level 3 & 19889 & Level 3 & 18609 \\
\hline Level 4 & 26519 & Level 4 & 21860 \\
\hline Level 5 & 36264 & Level 5 & 38514 \\
\hline \multicolumn{2}{|c|}{ Percobaan 7} & \multicolumn{2}{|c|}{ Percobaan 8} \\
\hline $\begin{array}{c}\text { Level } \\
\text { Percobaan } \\
\end{array}$ & $\begin{array}{c}\text { Keluaran Sensor } \\
\text { (Pulsa) }\end{array}$ & $\begin{array}{c}\text { Level } \\
\text { Percobaan }\end{array}$ & $\begin{array}{c}\text { Keluaran Sensor } \\
\text { (Pulsa) }\end{array}$ \\
\hline Level 3 & 15897 & Level 3 & 12211 \\
\hline Level 4 & 20836 & Level 4 & 17313 \\
\hline Level 5 & 38464 & Level 5 & 40264 \\
\hline
\end{tabular}




\begin{tabular}{|c|c|c|c|}
\hline \multicolumn{2}{|c|}{ Percobaan 9} & \multicolumn{2}{|c|}{ Percobaan 10} \\
\hline $\begin{array}{c}\text { Level } \\
\text { Percobaan }\end{array}$ & $\begin{array}{c}\text { Keluaran Sensor } \\
\text { (Pulsa) }\end{array}$ & $\begin{array}{c}\text { Level } \\
\text { Percobaan }\end{array}$ & $\begin{array}{c}\text { Keluaran Sensor } \\
\text { (Pulsa) }\end{array}$ \\
\hline Level 3 & 11918 & Level 3 & 17675 \\
\hline Level 4 & 21947 & Level 4 & 21948 \\
\hline Level 5 & 38992 & Level 5 & 40455 \\
\hline \multicolumn{4}{|c|}{$\begin{array}{r}\text { Rata-rata } \\
\end{array}$} \\
\hline Level & $\begin{array}{c}\text { Keluaran Sensor } \\
\text { (Pulsa) }\end{array}$ & \multicolumn{2}{|c|}{ Konversi (SR) } \\
\hline Level 3 & $16.322,6$ & \multirow{3}{*}{\multicolumn{2}{|c|}{$\begin{array}{c}5-6 \\
7-8 \\
9-10\end{array}$}} \\
\hline Level 4 & $22.889,9$ & & \\
\hline Level 5 & $38.602,4$ & & \\
\hline
\end{tabular}

\section{Pengujian Jarak Buzzer Terhadap Mikrofon}

Pengujian jarak buzzer terhadap mikrofon menjadi parameter yang penting terkait suara yang keluar dari buzzer. Suara tersebut nantinya akan dipancarkan oleh pemncar FM. Kalau mikrofon sangat dekat dengan buzzer maka akan menimbulkan derau, sebaliknya apabila jaraknya sangat jauh maka suara yang daoat dipancarkan pun menjadi lebih kecil. Pengujian jarak suara yang dapat diterima oleh mikrofon 24 $\mathrm{cm}$, dengan kualitas suara yang baik pada jarak $6-12 \mathrm{~cm}$.

\section{Pengujian Sistem}

Pengujian ini dilakukan untuk mengetahui seberapa jauh jarak pancar dari FM transmitter V2.0 sehingga suara dapat didengar oleh penerima FM secara maksimal. Ada dua hal yang mempengaruhi penerimaan sinyal pada receiver, yaitu jarak dan kebebasan terhadap transmitter [10]. Pada percobaan ini Pada Gambar 4 terlihat jarak antara pemancar dengan penerima yang dipancarkan oleh FM transmitter V2.0 sejauh 17,87 meter. Pada jarak ini, suara yng diterima oleh receiver dengan kondisi jelas sedangkan apabila jaraknya lebih dekat dari ini akan terjadi noise dengan perangkat yang terdekat. Apabila jarak lebih jauh maka suara yang didengar pada sisi receiver menjadi tidak jelas sehingga diperlukan antenna tambahan.

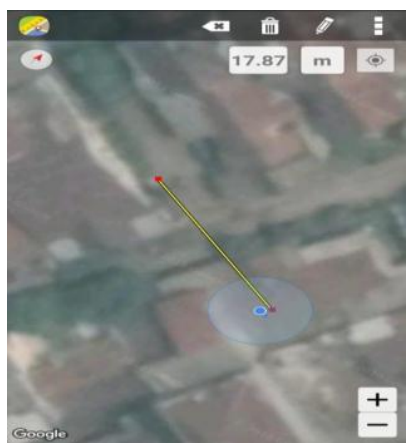

Gambar 4. Jarak Antar Pemancar dan Penerima

Pada penelitian [3] hanya mensimulasikan dengan memvariasikan daya dari sinyal yang dipancarkan. Variasi daya ini yang nantinya mengindikasi bahwa terjadi gempa. Sedangkan pada penelitian ini, sudah bisa membuat prototpe alat dengan suatu level getaran tertentu yang menandakan terjadinya gempa.

Penelitian lain [5] merancang sebuah prototype pendeteksi getaran menggunakan Raspberry Pi dan sensor getar SW-420. Sistem ini diterapkan untuk teknologi WLAN sedangkan pada saat terjadinya gempa yang besar seperti di Padang tahun 2008 akses komunikasi satu-satunya masih aktif yaitu radio. Oleh karena itu, penelitian ini menerapkan pada komunikasi FM dengan penerima adalah radio dan juga dengan harga lebih murah.

\section{KESIMPULAN}

Berdasarkan hasil dari perancangan sistem, pengujian dan pengukuran dalam penelitian ini maka didapatkan disimpulkan bahwa ketika level getaran 3-5 maka sensor akan aktif yang mengindikasikan bahwa terjadi gempa. Pulsa yang dihasilkan pada level 3-5 yakin 15.322,6 - 28.602,4 yang dikonversikan dalam SR menjadi 5-10 SR. Jarak terbaik agar suara alarm terdengar di sisi receiver dengan jangkauan $18,87 \mathrm{~m}$ sedangkan jarak 6-12 cm mengindikasikan bahwa terjadi gempa.

\section{UCAPAN TERIMAKASIH}

Penulis mengucapkan terimakasih kepada Lembaga Penelitian dan Pengabdian Masyarakat (LPPM) Universitas Jenderal Achmad Yani yang telah memberikan dana untuk penelitian tahun anggaran 2020.

\section{DAFTAR PUSTAKA}

[1] A.R. Timor, H. Andre, A. Hazmi, "Analisis Gelombang Elektromagnetik dan Seismik yang Ditimbulkan oleh Gejala Gempa", Jurnal Nasional Teknik Elektro, Vol. 5, No.3, pp. 316-324, November 2016.

[2] B. Mustafa, "Analisis Gempa Nias dan Gempa Sumatera Barat dan Kesamaannya yang Tidak Menimbulkan Tsunami', Jurnal Ilmu Fisika (JIF), Vol. 2, No. 1, pp 44-50, Maret 2020.

[3] Z. Jamal, "Pendeteksi Gempa dengan Metode FM Berbasis Personal Computer”, Jurnal Informatika, Vol. 11, No. 1, pp 77-89, Juni 2011.

[4] M.A. Novianta, E. Setyaningsih, "Rancang Bangun Sistem Deteksi Dini Gempa Bumi Berdasarkan Fluktuasi Medan Magnet Menggunakan Sensor MEMS", Jurnal Fakultas Teknik Universitas Muhammadiyah (Techno), Vol. 16, No.1, pp. 35-44, April 2015.

[5] J.F. Saputra, M. Rosmiati,M.I. Sari, "Pembangunan Prototype Sistem Monitoring Getaran Gempa Menggunakan Sensor Module SW-420", eProceeding of Applied Science, Vol. 4, No. 3, pp. 2055-2067, Desember 2018.

[6] Y. Yuliono, N. Paramytha, E. Fitriani, "Prototipe Pendeteksi Getaran Menggunakan Android Berbasis Mikrokontroler", Bina Darma Conference on Engineering Science, Vol. 1 No.1, pp. 124-133, Agustus 2019.

[7] A.R. Naldi, Wildian, "Rancang Bangun Sistem Alarm Gempa Bumi Menggunakan Prinsip Gaya Pegas dan Penginderaan Medan Magnetik", Jurnal Fisika Unand, Vol. 7,No. 4, pp 3724-378. Oktober 2018.

[8] H. Saman, M. Jamil, H. Saifudin, "Rancang Bangun Sistem Peringatan Dini Kebakaran Menggunakan Infrared Flame Detector Pararel dengan Arduino GSM/GPRS Shiled", Jurnal PROtek, Vol. 04, No. 1, pp 47-52. Mei 2017.

[9] A. Charisma, E. Taryana, D.I. Saputra, "Pemancar Pada Transmisi Energi Listrik Tanpa Kabel”, Seminar Nasional Sains dan Teknologi 2018, Oktober 2018.

[10] Arzul, Mirzazoni, "Perancangan dan Implementasi Sistem Monitoring And Controlling (MAC) Beban Listrik Ruangan Kuliah Menggunakan Wireless Sensor Network dan Arduino", Jurnal PROtek, Vol. 04, No. 1, pp. 1-4. Mei 2017.

Copyright @2016 PROtek : Jurnal Ilmiah Teknik Elektro (c) (i) (2) lisensi Creative Commons Attribution 4.0 International License 